\title{
Distribution of PCBs and PBDEs in soils along the altitudinal gradients of Balang Mountain, the east edge of the Tibetan Plateau
}

\author{
Xiaoyan Zheng ${ }^{\mathrm{a}, \mathrm{b}}$, Xiande Liu ${ }^{\mathrm{c}}$, Guibin Jiang ${ }^{\mathrm{a}}$, Yawei Wang ${ }^{\mathrm{a}, *}$, Qinghua Zhang ${ }^{\mathrm{a}}$, Yaqi Cai ${ }^{\mathrm{a}}$, Zhiyuan Cong ${ }^{\mathrm{d}}$ \\ ${ }^{a}$ State Key Laboratory of Environmental Chemistry and Ecotoxicology, Research Center for Eco-Environmental Sciences, Chinese Academy of Sciences, Beijing 100085, China \\ ${ }^{\mathrm{b}}$ China National Environmental Monitoring Center, Beijing 100012, China \\ ${ }^{\mathrm{C}}$ Chinese Research Academy of Environmental Sciences, Beijing 100012, China \\ ${ }^{\mathrm{d}}$ Institute of Tibetan Plateau Research, Chinese Academy of Sciences, Beijing 100085, China
}

\section{A R T I C L E I N F O}

\section{Article history:}

Received 19 May 2011

Received in revised form

10 September 2011

Accepted 19 September 2011

\section{Keywords:}

PCBs

PBDEs

Total organic carbon

Mountain cold-trapping effect

\begin{abstract}
A B S T R A C T
Surface soils were collected in Balang Mountain to explore the environmental process of polychlorinated biphenyls (PCBs) and polybrominated diphenyl ethers (PBDEs) during air transport. The average concentrations of $\sum_{25} \mathrm{PCBs}$ and $\sum_{13} \mathrm{PBDEs}$ in soils were $163 \mathrm{pg} / \mathrm{g}$ and $26 \mathrm{pg} / \mathrm{g}$, respectively. The significant correlations between the concentrations of pollutants and total organic carbon (TOC) indicated the importance of TOC in accumulation potential of POPs. The slopes from fitted curves of PCBs were highly related with $\log K_{\mathrm{oa}}$, demonstrating that TOC dominates the soil-air exchange of PCBs. The TOCnormalized concentrations of contaminants in samples from below-treeline were higher than those from alpine meadow, probably due to the forest filter effect. The increasing trends of the concentrations with altitude from the alpine meadow samples, could be attributed to the mountain cold-trapping effect. And the weak cold-trapping effect of POPs might be due to the less precipitation in 2008 when comparing with those in 2006.
\end{abstract}

(c) 2011 Elsevier Ltd. All rights reserved.

\section{Introduction}

Polychlorinated biphenyls (PCBs) and polybrominated diphenyl ethers (PBDEs) are two groups of semivolatile organic compounds (SVOCs). The compounds are persistent and not readily undergoing degradation when released into the environment. These several groups of persistent organic compounds (POPs) are of concern to humans and wildlife because of their toxicity and bioaccumulation capacity (Axmon et al., 2008; Lunder et al., 2010). PCBs and PBDEs are also known for long range transport abilities, and have been detected in the remote areas and alpine mountains (Hites et al., 2004; Gallego et al., 2007; Chen and Hale, 2010).

Owing to the temperature-driven evaporation/deposition among different latitudes, these SVOCs undergo the global distillation during the long range transport (Wania and Mackay, 1993, 1996). When compared with the worldwide scales, high mountain areas also have a wide range of temperature with increasing altitude. The occurrence of POPs in various environmental matrices all over high mountain areas suggests orographic cold-trapping of

\footnotetext{
* Corresponding author.

E-mail addresses: xiaoyanzheng1978@gmail.com (X. Zheng), xiande.liu@gmail.com (X. Liu), gbjiang@rcees.ac.cn (G. Jiang), ywwang@rcees.ac.cn (Y. Wang).
}

the POPs have occurred in these regions with air movement (Blais et al., 1998; Daly and Wania, 2005). Recently precipitation was proposed as an efficient scavenger of POPs in alpine mountains (Daly and Wania, 2004; Stocker et al., 2007). Some studies revealed that an orographically lift led to a high precipitation rate with altitude, and the wet deposition was hypothesized to be mainly responsible for the contaminant enrichment in mountains, which had been further evidenced by model calculation (Wania and Westgate, 2008) and field studies (Chen et al., 2008; Tremolada et al., 2008; Grimalt et al., 2009; Shen et al., 2009). Moreover, because of their simple plant and animal communities, mountain ecosystems were vulnerable to contamination by SVOCs (Sparling et al., 2001). Therefore the study on the mountain cold-trapping mechanism of SVOCs is meaningful.

The Tibetan Plateau is the largest and highest plateau and commonly called the roof of the world, having a $2.5 \times 10^{6} \mathrm{~km}^{2}$ zone with an average elevation of over $4500 \mathrm{~m}$. Previous works have found that POPs and other contaminants might be particularly pronounced in the plateau due to the orographic cold-trapping effect, especially in the southeast Tibetan Plateau (Cheng et al., 2007; Yang et al., 2008, 2010; Wang et al., 2009, 2010). The east edge of the Tibetan Plateau is located between populous Chendu Plain and the Tibetan Plateau with steep altitudinal gradients, which offers a remarkable and unique site to study the cold- 
trapping mechanism of POPs. However, only limited works on POPs have been evaluated in this transition area (Chen et al., 2008; Zheng et al., 2009; Liu et al., 2010).

In the present study, PCB and PBDE concentrations were analyzed in soil samples collected along the southeast slope of Balang Mountain in Wolong Natural Reserve (WNR), which is far away from human residential sites. This work was the complement to our previous study on OCPs and PCBs in soils (Chen et al., 2008; Zheng et al., 2009) and air (Liu et al., 2010) in WNR, to further assess the potential of mountain cold-trapping in this area and to understand the role of underlying environmental factors (such as atmospheric transport, vegetation cover, and precipitation etc.), concentrations, congener profiles and altitudinal patterns of POPs in alpine mountains.

\section{Materials and methods}

\subsection{Regional characterization and soil sampling}

The southeast slope of Balang Mountain (about $30^{\circ} \mathrm{N}, 103^{\circ} \mathrm{E}$ ) (Fig. 1) belongs to Wolong Nature Reserve (WNR), Sichuan province, China. It is located on the east edge of the Tibetan Plateau with a strong gradient which is characteristic of its topography. Atmospheric circulation in this area is mainly governed by the air mass from Western China, especially from the Chengdu Plain (Fig. S1). The area is different from the heartland of the Tibetan Plateau which is dominated by continental air from central Asia and maritime air from the Indian Ocean. Two consecutive rivers, Yuzi Brook and Pitiao River, flow through WNR. The average temperature lapse rate is $0.6{ }^{\circ} \mathrm{C} / 100 \mathrm{~m}$ with increasing altitude and precipitation is approximately $800 \mathrm{~mm}$ at $1800 \mathrm{~m}$ a.s.l. and rises to nearly $50 \%$ at $4500 \mathrm{~m}$ a.s.l. More information and meteorological conditions about the sampling area can be found in our previous works (Chen et al., 2008; Zheng et al., 2009; Liu et al., 2010).

In this study, seven sampling sites were selected from Balang Mountain with an increasing altitude in the range from 1439 to $4479 \mathrm{~m}$ a.s.l. Based on the vegetation zone, these sampling sites were divided into two groups: that is to say the alpine meadow and below-treeline (Table 1). Three sampling sites of below-treeline (Site 1 , 2, and 3) were up from Yuzi Brook to the vicinity of the headwater of Pitiao River, and the remained belonged to the alpine meadow ones.

Soil samples were collected in April, 2008. An organic-rich, dark-colored surface layer (5-10 cm depth) could be generally discernable in the sampling area. Thus ten to fifteen surface pits were randomly dug in a 50 -m diameter circle by a stainless steel shovel. They were then mixed into a homogeneous sample. After freeze-dried and sieved, $2-3$ subsamples were separated. In all, 18 soil subsamples were sealed in zipper bags and stored at $-18{ }^{\circ} \mathrm{C}$ until analysis. Total organic carbon (TOC) of soils was measured for one subsample of each site using a CHN elemental analyzer (MT-5) described by Chi et al. (1999). The details of sampling sites (annual average temperature, geographic position, TOC, etc.) were presented in Table 1.

\subsection{Extraction, clean-up and analysis}

In brief, $5 \mathrm{~g}$ of soil were extracted on an accelerated solvent extraction (ASE 300) using 1:1 dichloromethane/hexane. $1 \mathrm{ng}{ }^{13} \mathrm{C}$-labelled PCBs (EPA 68A-LCS) and ${ }^{13} \mathrm{C}$ labelled PBDEs $\left({ }^{13} \mathrm{C}\right.$-BDE-47, 99, 153) were spiked as surrogates and quantification standards before extraction. After rotary evaporation and concentration, the extract was cleaned with hexane on a multilayer silica gel column containing $1 \mathrm{~g}$ silica gel, $4 \mathrm{~g}$ basic silica gel, $1 \mathrm{~g}$ silica gel, $8 \mathrm{~g}$ acid silica gel, $2 \mathrm{~g}$ silica gel and $2 \mathrm{~cm}$ anhydrous sodium sulfate from bottom to top. Finally, the resultant elution was reduced to about $25 \mu \mathrm{L}$ and $1 \mathrm{ng}{ }^{13} \mathrm{C}$-labelled PCBs (EPA 68A-IS) were added as internal
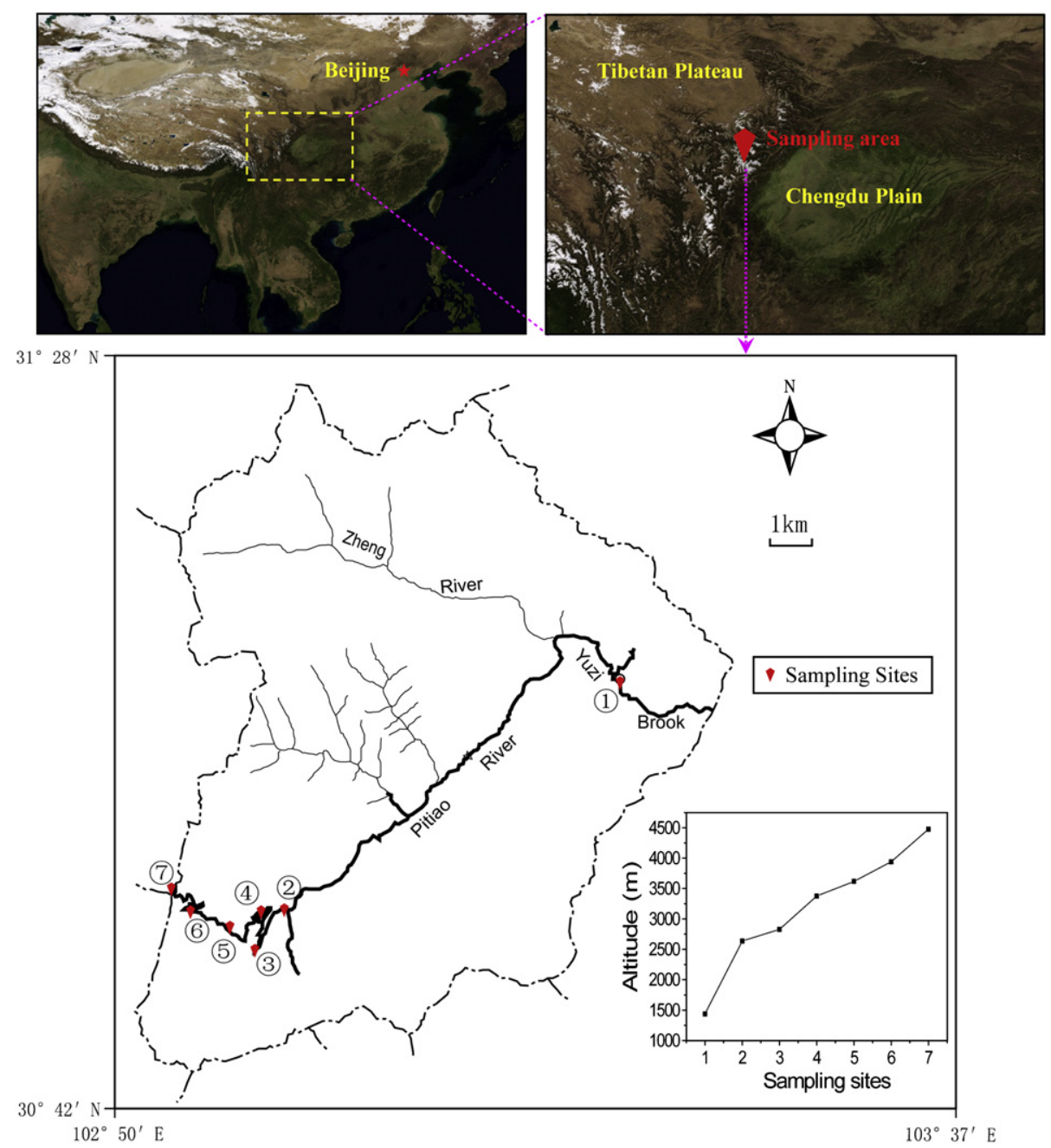

Fig. 1. The geographic location and altitude of sampling sites. 
Table 1

Information on sampling sites and soil samples.

\begin{tabular}{|c|c|c|c|c|c|c|c|}
\hline Site & Name & Altitude $(\mathrm{m}) / \mathrm{T}\left({ }^{\circ} \mathrm{C}\right)$ & Longitude (E) & Latitude $(\mathrm{N})$ & Samples & \%TOC & Vegetation \\
\hline 1 & Gengda & $1439 / 14.5$ & $103^{\circ} 18.72^{\prime}$ & $31^{\circ} 05.08^{\prime}$ & 2 & 4.85 & Indeciduous/deciduous broadleaved mixed fores \\
\hline 2 & Lvlvdian & $2636 / 7.3$ & $102^{\circ} 59.36^{\prime}$ & $30^{\circ} 53.22^{\prime}$ & 2 & 18.7 & Coniferous-broadleaved mixed forest \\
\hline 3 & Dengsheng & $2828 / 6.1$ & $102^{\circ} 58.34^{\prime}$ & $30^{\circ} 51.48^{\prime}$ & 2 & 9.34 & Cold temperature conifer forest \\
\hline 4 & Beimuping & $3377 / 2.8$ & $102^{\circ} 58.91^{\prime}$ & $30^{\circ} 53.80^{\prime}$ & 3 & 11.9 & Alpine scrub-meadow \\
\hline 5 & $95 \mathrm{~km}$ milestone & $3619 / 1.4$ & $102^{\circ} 57.37^{\prime}$ & $30^{\circ} 52.40^{\prime}$ & 3 & 10.9 & Alpine meadow \\
\hline 6 & Tangfang & $3940 /-0.5$ & $102^{\circ} 54.27^{\prime}$ & $30^{\circ} 53.60^{\prime}$ & 3 & 5.67 & Alpine meadow \\
\hline 7 & Pass & $4479 /-3.8$ & $102^{\circ} 53.74^{\prime}$ & $30^{\circ} 54.69^{\prime}$ & 3 & 13.2 & Alpine meadow \\
\hline
\end{tabular}

standards for calculating surrogates recovery. In all, 25 PCB congeners including mono-CB 3, di-CB-15; tri-CB-19, 28; tetra-CB-52, 77, and 81; penta-CB-101, 105, 114 118,123 , and 126; hexa-CB-138, 153, 156, 157, 167, and 169; hepta-CB-180 and 189; octa-CB -202 and 205; nona-CB-208 and deca-CB-209 and 13 PBDEs (BDE-17, 28, 47, $66,71,85,99,100,138,153,154,183$ and 190 ) were quantified. The results were obtained using high resolution gas chromatography coupled with high resolution mass spectrometry, based on an isotope dilution method. A detailed description of the analytical procedure and instrument conditions could also be found in Wang et al. (2009).

All analytical solvents were of pesticide grades. One procedural blank was performed for every 8 samples. The detected PCB concentrations were detected less than $5 \%$ of those in soils while PBDEs were slightly higher than $15 \%$. Therefore PBDEs in soils were blank corrected whereas PCBs were not. The method detection limit ranged from $0.023 \mathrm{pg} / \mathrm{g}$ for CB-202 to $0.163 \mathrm{pg} / \mathrm{g}$ for CB-153. The mean recoveries for surrogate PCBs and PBDEs were $61-137 \%$ and $68-80 \%$, respectively.

\section{Results and discussion}

\subsection{Concentrations of PCBs and PBDEs}

The concentrations of PCBs and PBDEs on the basis of dry weight (dw) are summarized in Table 2 . $\sum_{25}$ PCBs in soils ranged from 59 to $287 \mathrm{pg} / \mathrm{g}$ with an average value of $163 \mathrm{pg} / \mathrm{g}$, These concentrations are comparable to the ones reported by Wang et al. (2009) in soils from the Tibetan Plateau (mean value $186 \mathrm{pg} / \mathrm{g}$ ) and lower than the PCB concentrations $(424 \mathrm{pg} / \mathrm{g})$ in soils from Chinese background areas (Ren et al., 2007), global background levels (5410 pg/g) (Meijer et al., 2003), and an Italian mountain near a regional industrial source $(3600 \pm 2300 \mathrm{pg} / \mathrm{g})$ (Tremolada et al., 2008), whereas higher than those of Peru mountain $(80 \pm 140 \mathrm{pg} / \mathrm{g})$ (Tremolada et al., 2008). The main congeners were tri-CBs and hexa-CBs, which accounted for $48.2 \%$ and $17.5 \%$ of $\sum{ }_{25} \mathrm{PCBs}$, respectively. A recent study also reported that di- and tri-CBs were the dominant congeners in soils from remote/farm region while

Table 2

Mean and range of concentrations (pg/g dw) of indicator PCBs and PBDEs ${ }^{\mathrm{a}}$ in Balang Mountain soils.

\begin{tabular}{lcc}
\hline Congener & Mean & Range \\
\hline CB-28 & 79 & $26-151$ \\
CB-52 & 9.1 & $4.0-17$ \\
CB-101 & 7.4 & $2.7-15$ \\
CB-118 & 5.8 & $1.4-14$ \\
CB-138 & 11 & $3.1-22$ \\
CB-153 & 15 & $4.6-33$ \\
CB-180 & 2.8 & $0.2-13$ \\
$\sum$ 25CBs & 163 & $59-287$ \\
BDE-17 & 1.3 & $0.5-3.1$ \\
BDE-28 & 5.7 & $1.1-14$ \\
BDE-47 & 5.6 & $1.7-10$ \\
BDE-66 & 1.6 & $0.4-4.3$ \\
BDE-99 & 1.5 & $0.3-3.8$ \\
BDE-100 & 0.3 & $0.1-0.7$ \\
BDE-153 & 8.2 & $0.05-35$ \\
BDE-154 & 0.4 & $0.05-0.7$ \\
BDE-183 & 2.2 & $0.3-4.6$ \\
$\sum 13$ PBDEs & 26 & $4.3-61$ \\
\hline
\end{tabular}

a BDE-71, BDE-85, BDE-138 and BDE-190 were under the LOD.
hexa-CB and tri-CB were the main congeners of those from urban area in China (Ren et al., 2007). Seven indicator PCBs (including CB$28,52,101,118,153,138$, and 180 ) were detected in all samples with concentration ranges of $0.2-151 \mathrm{pg} / \mathrm{g}$, which accounted for $71 \%-$ $84 \%$ of $\sum_{25}$ PCBs. A significant linear relationship was observed between $\Sigma_{7} \mathrm{PCBs}$ and $\sum_{25} \mathrm{PCBs}(R=0.997, P<0.01)$, suggesting that indicator PCBs could represent the environmental fate and transport of 25 PCBs in this area.

Total toxic equivalency (TEQ) of dioxin-like PCBs were also calculated using the World Health Organization toxic equivalency factors (Van den Berg et al., 1998), and their values ranged between 22 and $94 \mathrm{fg}^{\mathrm{TEQ} \mathrm{g}^{-1}}$. TEQ values in our study are lower than those

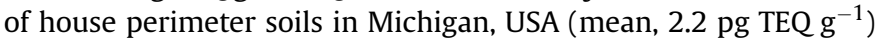
(Hong et al., 2009).

In the present study, $\sum_{13}$ PBDEs in this study varied from 4.3 to $61 \mathrm{pg} / \mathrm{g}$ with an average value of $26 \mathrm{pg} / \mathrm{g}$. These levels were comparable to those in soils from the south Tibetan Plateau (mean, $11 \mathrm{pg} / \mathrm{g}$ ) (Wang et al., 2009), but much lower than other remote regions, such as Russian Arctic (16-230 pg/g) (de Wit et al., 2006) and European background soils (65-12,000 pg/g) (Hassanin et al., 2004). The main congeners found were lowly brominated such as BDE-28 and 47. An air investigation across Asia also observed that these two congeners were the major compounds across Mid-east China, including the Chengdu Plain (Jaward et al., 2005b), which implied that PBDEs in Balang Mountain soils might be introduced and controlled by atmospheric transport of the Chengdu Plain (Liu et al., 2010).

From the comparison above, it can be seen that PCB and PBDE concentrations in WNR were at the lower end of worldwide levels. Therefore this area can be regarded as a pristine area on a global scale.

\subsection{The role of soil total organic carbon}

Total organic carbon (TOC) of soil is an ideal pool for accumulating POPs deposition from the atmosphere. Table 1 shows the $\%$-TOC data in each site, and is in agreement with our previous studies (Chen et al., 2008; Zheng et al., 2009). Significant linear relationships $(p<0.01)$ were found between TOC and $\sum{ }_{25}$ PCBs and $\sum_{13}$ PBDEs concentrations in soil samples. The correlations between TOC and the concentration of individual congeners were also calculated (Table S1). In order to diminish the scatter in the data, the concentrations of congeners and \%TOC were log transformed before regression. It was observed that the majority of individual congener concentrations had significant linear relationships with the TOC, suggesting that the importance of TOC in accumulation potential of POPs. The results were consistent with the results of other related works in alpine mountains such as south Tibetan Plateau, subtropical Atlantic, and European background areas (Ribes et al., 2002; Meijer et al., 2003; Hassanin et al., 2004; Wang et al., 2009).

In general, soil organic matter dominates the soil-air distribution of POPs (Ribes et al., 2002; Daly et al., 2007; Shen et al., 2009). 
The transport of a compound between the boundary of soils and atmosphere is highly dependent on its $K_{\text {oad }}$. The slopes at the significant level from Table S1 were related with corresponding $\log K_{\mathrm{oa}}$ and the curve of PCBs is shown in Fig. 2. In this context $K_{\mathrm{oa}}$ of PCBs were calculated according to the equation reported by Harner and Bidleman (1996). The significant linear relationships might imply that PCB concentrations in Balang Mountain soils evidently depended on their $K_{\text {oa }}$ and soil TOC. The distribution patterns might have reached a steady-state with the soil properties, which is in accordance with the observation results in Teide Mountain (Ribes et al., 2002).

The same procedure was also practiced for PBDEs. $\log K_{\text {oa }}$ of PBDEs were computed through the equation obtained from the work of Harner and Shoeib (2002) (Table S1). Unlike the PCB results, no significant relationship was found between slope and $\log K_{\text {oa }}$ for PBDEs (Fig. 2). It seemed that different usage history of these two kinds of POPs might have led to this inverse phenomenon. This was similar to the results of PCBs and PBDEs in fish from European high mountain lake (Gallego et al., 2007).

\subsection{Altitudinal distribution of $P C B$ and $P B D E$ concentrations}

TOC-normalized concentrations of contaminants in soils can actually represent their accumulation and distillation and minimize the influence of other factors, such as proximity to source region, vegetation coverage, climatic conditions and so on (Hassanin et al., 2004; Tremolada et al., 2008).

Figs. 3, S2 and S3 show the distribution trends of TOCnormalized PCB and PBDE concentrations along the altitudinal gradient in this study (Tables S2 and S3). The samples collected from the below-treeline sites had relative higher concentrations of these two groups of POPs. The concentrations were comparable to those of the alpine meadow sampling sites and also similar to our previous result on OCPs in this area (Zheng et al., 2009). Forests can accumulate organic pollutants by gaseous uptake and atmospheric deposition, and eventually transfer them to forest soil (McLachlan, 1999; Wania and McLachlan, 2001; Nizzetto et al., 2006). A model estimated that the concentrations of SVOCs in soils could increase by $28 \%$ for areas with forest than without forest (Wania and McLachlan, 2001). Considering the uniform air concentrations of chemicals along the transect (Liu et al., 2010), the forest filter effect could be responsible for the higher levels in the below-treeline soils in Balang Mountain. It was found the highest levels of PCBs and

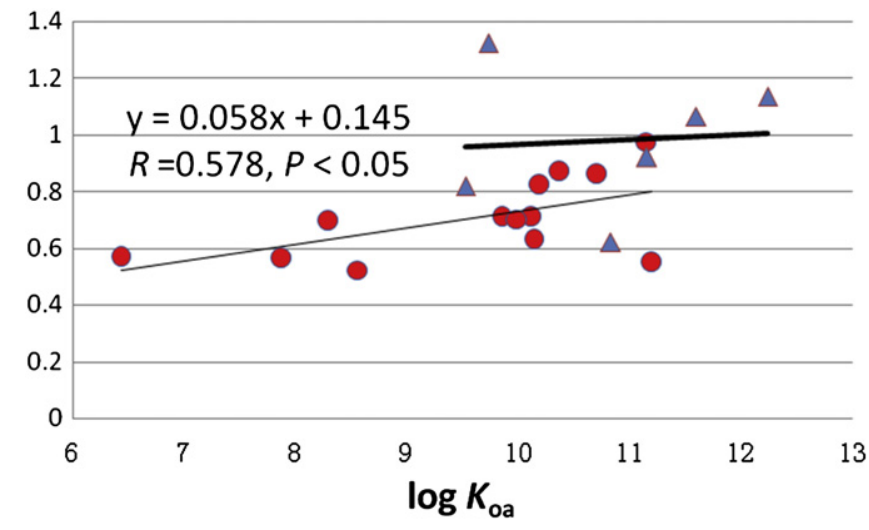

Fig. 2. The slopes derived from the correlation of the concentration of $\mathrm{PCBs}$ and PBDEs vs. \%TOC (excluded PCB202 and 209) as related to $\log K_{\text {oa. }}$. The red dots represent PCBs and blue triangles are PBDEs. The regression equation represents the correlation between slope and $\log K_{\text {oa }}$ of PCBs. The slopes at significant level are selected (Table S1). (For interpretation of the references to color in this figure legend, the reader is referred to the web version of this article.)
PBDEs existed in Site 1 (Figs. 3, S2 and S3, Tables S2 and S3). The proximity of the human residence (the Chendu Plain) might be another possible source apart from the forest filter.

However, the results also revealed that the concentrations of some congeners increased with altitude in the alpine meadow area. Since the cold-trapping effect preferred to be focused on the alpine meadow sites (Zheng et al., 2009), a linear regression of the logarithm of soil concentration ( $\mathrm{C}_{\text {soil }}$ in $\mathrm{ng} / \mathrm{g} \mathrm{TOC}$ ) on height ( $\mathrm{h}$ in meter) was performed for those samples above the treeline in Balang Mountain (Chen et al., 2008):

$\log \mathrm{C}_{\text {soil }}=m \times \mathrm{h}+\mathrm{c}$,

Table 3 includes parameters only if a regression analysis was significant $(p<0.1)$. Evidence of mountain cold-trapping effect for some chemicals was observed when the samples from alpine meadow were involved. The results showed that $m$ of low-chlorinated biphenyls were negative while $m$ of heavier compounds were basically positive. Moreover, congeners with higher $K_{\text {oa }}$ had larger $m$, including CB-105, 123, 138, 153, 156, 167, 208 and BDE-47, 66, 99, 153. This meant more distinct enhancement with altitude, which was agreed with more abundant precipitation at higher altitude. Without the interferences of plant foliage and other obvious sources, the temperature-dependent precipitation would be the dominant deposition pathway in the mountain areas. The volatilities of these substances have been found to be about two orders of magnitude less than those experienced global cold-trapping (Wania and Westgate, 2008). Thereby heavier SVOCs were more easily cold-trapped by soils of alpine meadow in contrast with lighter chemicals in Balang Mountain, indicating precipitation was the prominent factor of mountain cold-trapping in this region.

\subsection{Altitudinal distribution of $P C B$ and PBDE homologues}

Fig. 3 also displays the homologues composition analysis for PCBs and PBDEs along the elevation. In comparison to the results of the OCPs and PCBs increased with altitude in this area in 2006 (Chen et al., 2008), it could be seen that CB-28, which was the most predominant congener for PCBs, showed opposite decreasing trend with the elevation in this study. The possible reason might be the reduction of precipitation in the year before sampling (Jiang and $\mathrm{Li}$, 2008). Annual precipitation in 2007 and 2008 was about $67 \%$ of that in 2006, which might lead to a weak cold-trapping effect of POPs. As mentioned above precipitation was apt to scavenge more efficiency for heavier SVOCs. Therefore, low-chlorinated PCBs (such as $\mathrm{CB}-28$ ) were less cold-trapped and even less so during a low precipitation period (Wania and Westgate, 2008). For PCBs, the percentage of dominant congener tri-CBs was increasing with elevation in the below-treeline area, and decreased with elevation in the alpine meadow area. While for hexa-CBs, another kind of dominant congeners, an opposite trend was found. The vegetation preferred to absorb POPs with higher $K_{\text {oa }}$ from the air, which would result in a decreasing percentage of hexa-CBs in air and, in turn, in vegetation and soil along the altitude in the below-treeline area, which is called the forest filter effect (Jaward et al., 2005a). However, the cold-trapping effect showed up in the alpine meadow area at higher altitudes, which made the increasing trends of the percentage of hexa-CBs increased (Table S4). For PBDEs, the two major congeners BDE-47 and 28 had no obvious spatial trends with increasing altitude.

A significant relation between the concentration of PCBs and PBDEs (excluded Site 7) implied their similar altitudinal patterns although they have different usage history (Fig. S4). It reflected that they might be from the same industrial emission source. It was surprising that the fraction of BDE-153 at Site 7 was much higher 

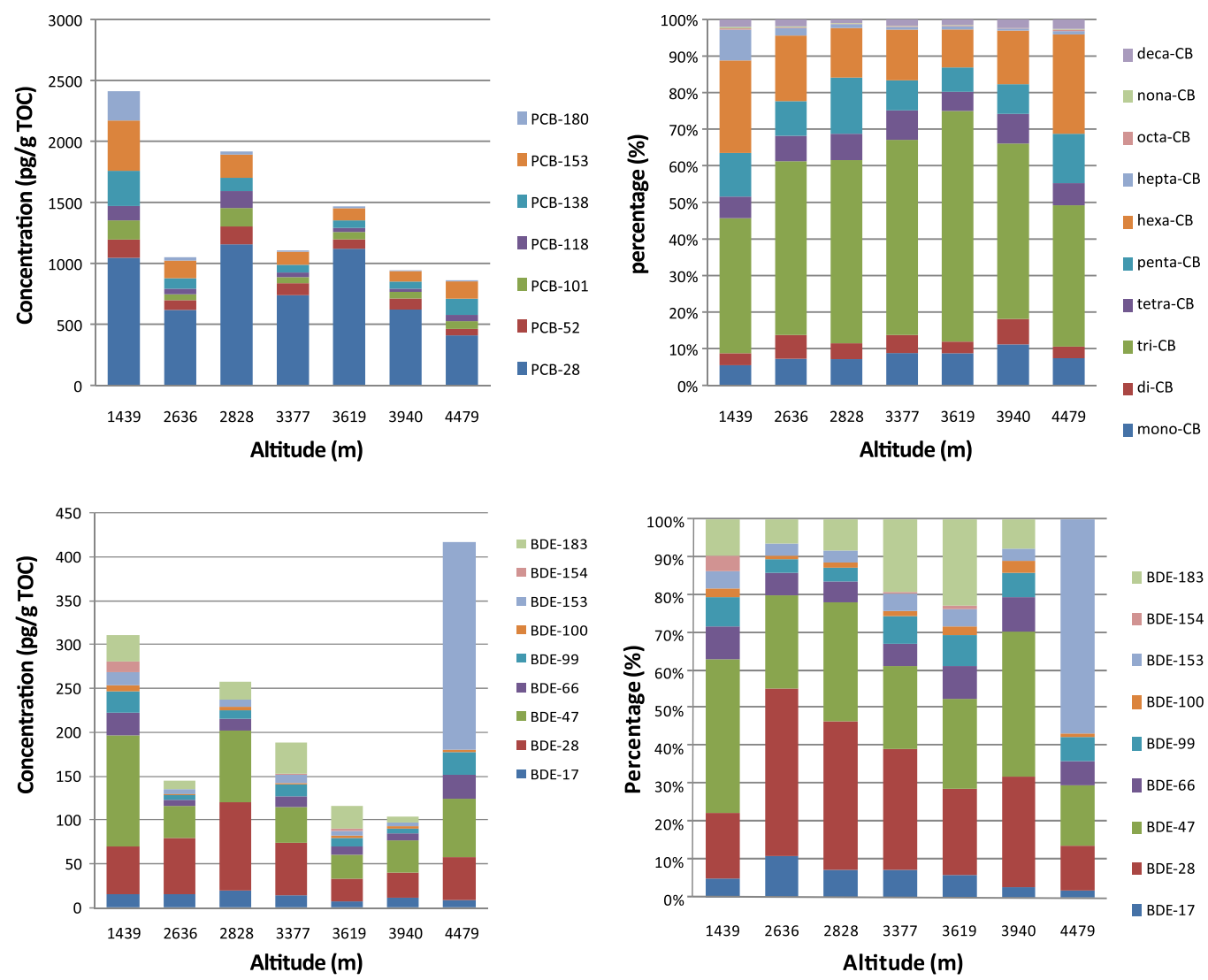

Fig. 3. Concentrations and composition percent (\%) of PCBs and PBDEs in soils along the altitude.

than those in other sampling sites. Considering the good repeatability of samples of the analytical method, the operation mistakes and analysis errors were excluded. The possible reason for phenomenon was due to the human disturbance. Site 7 was located at the pass of pilgrimage in Balang Mountain, where local residents often hung many sutra streamers and hadas. They are made of textile with painting. The printed paper was also scattered for the religious activities in this area. The textile and paint may contain PBDEs, which probably resulted in the high concentrations of BDE153 at site 7 (Hale et al., 2002; Kemmlein et al., 2003; Watanabe and Sakai, 2003).

Table 3

Parameters for exponential equation of PCBs and PBDEs concentrations in soils from alpine meadow sites (ng/g TOC) against elevation.

\begin{tabular}{lcrl}
\hline & $m .10^{-4}$ & $R$ & $p$ \\
\hline C-B3 & -2.15 & -0.716 & 0.00595 \\
CB-15 & -2.53 & -0.567 & 0.0434 \\
CB-28 & -3.11 & -0.763 & 0.00243 \\
CB-52 & -2.36 & -0.814 & $7.10 \mathrm{E}-4$ \\
CB-105 & 1.33 & 0.483 & 0.0942 \\
CB-123 & 0.778 & 0.511 & 0.0744 \\
CB-138 & 2.97 & 0.796 & 0.00115 \\
CB-153 & 1.27 & 0.555 & 0.0489 \\
CB-156 & 3.28 & 0.638 & 0.0190 \\
CB-167 & 2.32 & 0.483 & 0.0946 \\
CB-169 & -2.04 & -0.513 & 0.0733 \\
CB-208 & 1.58 & 0.555 & 0.0962 \\
BDE-47 & 2.62 & 0.731 & 0.0045 \\
BDE-66 & 3.78 & 0.738 & 0.00397 \\
BDE-99 & 3.20 & 0.523 & 0.0666 \\
BDE-153 & 14.5 & 0.757 & 0.00275 \\
BDE-183 & -12.3 & -0.939 & $1.71 \mathrm{E}-4$ \\
\hline
\end{tabular}

\section{Conclusion}

The concentrations of PCBs and PBDEs in soils from Balang Mountain were at low end level in the worldwide. The coldtrapping effect for PCBs and PBDEs could be found in the alpine meadow area. High concentrations of PCBs and PBDEs in the below-treeline area elucidated that forests could act as a filter for contaminants. Precipitation was a key factor for POPs enrichment in Balang Mountain, which enhanced the deposition rate of some heavier substances with elevations. On the basis of the concentration levels, altitude distributions and homologue profiles of PCBs and PBDEs, atmospheric transport was concluded to be the main origin source of POPs.

\section{Acknowledgements}

We are grateful to $\mathrm{Li}$ Jun and Wang $\mathrm{Pu}$ for their technical assistance in field sampling and data analysis. We also deeply appreciate the reviewers for excellent suggestions. This work is jointly supported by the National Basic Research Program of China (2009CB421605), Natural Science Foundation of China (21177149, 20890111, 41101476), and China Postdoctoral Science Foundation funded project (20090460545, 201003167).

\section{Appendix. Supplementary material}

Supplementary material associated with this article can be found, in the online version, at doi:10.1016/j.envpol.2011. 09.036 . 


\section{References}

Axmon, A., Rylander, L., Rignell-Hydbom, A., 2008. Reproductive toxicity of seafood contaminants: prospective comparisons of Swedish east and west coast fishermen's families. Environmental Health 7.

Blais, J.M., Schindler, D.W., Muir, D.C.G., Kimpe, L.E., Donald, D.B., Rosenberg, B., 1998. Accumulation of persistent organochlorine compounds in mountains of western Canada. Nature 395, 585-588.

Chen, D., Hale, R.C., 2010. A global review of polybrominated diphenyl ether flame retardant contamination in birds. Environment International 36, 800-811.

Chen, D.Z., Liu, W.J., Liu, X.D., Westgate, J.N., Wania, F., 2008. Cold-trapping of persistent organic pollutants in the mountain soils of Western Sichuan, China. Environmental Science and Technology 42, 9086-9091.

Cheng, H.R., Zhang, G., Jiang, J.X., Li, X.D., Liu, X., Li, J., Zhao, Y.C., 2007. Organochlorine pesticides, polybrominated biphenyl ethers and lead isotopes during the spring time at the Waliguan Baseline Observatory, northwest China: implication for long-range atmospheric transport. Atmospheric Environment 41, 4734-4747.

Chi, X.G., Di, Y.A., Dong, S.P., Liu, X.D., 1999. Determination of atmospheric aerosol organic carbon and elemental carbon. Environmental Monitoring of China 15, 11-13 (in Chinese).

Daly, G.L., Wania, F., 2004. Simulating the influence of snow on the fate of organic compounds. Environmental Science and Technology 38, 4176-4186.

Daly, G.L., Wania, F., 2005. Organic contaminants in mountains. Environmental Science and Technology 39, 385-398.

Daly, G.L., Lei, Y.D., Teixeira, C., Muir, D.C.G., Wania, F., 2007. Pesticides in western Canadian mountain air and soil. Environmental Science and Technology 41, 6020-6025.

de Wit, C.A., Alaee, M., Muir, D.C.G., 2006. Levels and trends of brominated flame retardants in the Arctic. Chemosphere 64, 209-233.

Gallego, E., Grimalt, J.O., Bartrons, M., Lopez, J.F., Camarero, L., Catalan, J., Stuchlik, E., Battarbee, R., 2007. Altitudinal gradients of PBDEs and PCBs in fish from European high mountain lakes. Environmental Science and Technology 41, 2196-2202.

Grimalt, J.O., Fernadez, P., Quiroz, R., 2009. Input of organochlorine compounds by snow to European high mountain lakes. Freshwater Biology 54, 2533-2542.

Hale, R.C., La Guardia, M.J., Harvey, E., Matt Mainor, T., 2002. Potential role of fire retardant-treated polyurethane foam as a source of brominated diphenyl ethers to the US environment. Chemosphere 46, 729-735.

Harner, T., Bidleman, T.F., 1996. Measurements of octanol-air partition coefficients for polychlorinated biphenyls. Journal of Chemical and Engineering Data 41, 895-899.

Harner, T., Shoeib, M., 2002. Measurements of octanol- air partition coefficients $\left(K_{\mathrm{OA}}\right)$ for polybrominated diphenyl ethers (PBDEs): predicting partitioning in the environment. Journal of Chemical and Engineering Data 47, 228-232.

Hassanin, A., Breivik, K., Meijer, S.N., Steinnes, E., Thomas, G.O., Jones, K.C., 2004 PBDEs in European background soils: levels and factors controlling their distribution. Environmental Science and Technology 38, 738-745.

Hites, R.A., Foran, J.A., Carpenter, D.O., Hamilton, M.C., Knuth, B.A., Schwager, S.J., 2004. Global assessment of organic contaminants in farmed salmon. Science 303, 226-229.

Hong, B.L., Garabrant, D., Hedgeman, E., Demond, A., Gillespie, B., Chen, Q.X., Chang, C.W., Towey, T., Knutson, K., Franzblau, A., Lepkowski, J., Adriaens, P. 2009. Impact of WHO 2005 revised toxic equivalency factors for dioxins on the TEQs in serum, household dust and soil. Chemosphere 76, 727-733.

Jaward, F.M., Di Guardo, A., Nizzetto, L., Cassani, C., Raffaele, F., Ferretti, R. Jones, K.C., 2005a. PCBs and selected organochlorine compounds in Italian Mountain air: the influence of altitude and forest ecosystem type. Environmental Science \& Technology 39, 3455-3463.

Jaward, F.M., Zhang, G., Nam, J.J., Sweetman, A.J., Obbard, J.P., Kobara, Y., Jones, K.C. 2005b. Passive air sampling of polychlorinated biphenyls, organochlorine compounds, and polybrominated diphenyl ethers across Asia. Environmental Science and Technology 39, 8638-8645.

Jiang, X.W., Li, Y.Q., 2008. The statistical analysis of earthquake and precipitation in Sichuan Province. Plateau Mountain Meteorology Research 128, 33-36 (in Chinese).

Kemmlein, S., Hahn, O., Jann, O., 2003. Emissions of organophosphate and brominated flame retardants from selected consumer products and building materials. Atmospheric Environment 37, 5485-5493.
Liu, W.J., Chen, D.Z., Liu, X.D., Zheng, X.Y., Yang, W., Westgate, J.N., Wania, F., 2010 Transport of semivolatile organic compounds to the Tibetan Plateau: spatial and temporal variation in air concentrations in mountainous western Sichuan, China. Environmental Science and Technology 44, 1559-1565.

Lunder, S., Hovander, L., Athanassiadis, I., Bergman, A., 2010. Significantly higher polybrominated diphenyl ether levels in young U.S. children than in their mothers. Environmental Science and Technology 44, 5256-5262.

McLachlan, M.S., 1999. Framework for the interpretation of measurements of SOCs in plants. Environmental Science and Technology 33, 1799-1804.

Meijer, S.N., Ockenden, W.A., Sweetman, A., Breivik, K., Grimalt, J.O., Jones, K.C., 2003. Global distribution and budget of PCBs and HCB in background surface soils: implications for sources and environmental processes. Environmental Science and Technology 37, 667-672.

Nizzetto, L., Cassani, C., Di Guardo, A., 2006. Deposition of PCBs in mountains: the forest filter effect of different forest ecosystem types. Ecotoxicology and Environmental Safety 63, 75-83.

Ren, N.Q., Que, M.X., Li, Y.F., Liu, Y., Wan, X.N., Xu, D.D., Sverko, E., Ma, J.M., 2007 Polychlorinated biphenyls in Chinese surface soils. Environmental Science and Technology 41, 3871-3876.

Ribes, A., Grimalt, J.O., Garcia, C.J.T., Cuevas, E., 2002. Temperature and organic matter dependence of the distribution of organochlorine compounds in mountain soils from the subtropical Atlantic (Teide, Tenerife Island). Environmental Science and Technology 36, 1879-1885.

Shen, H., Henkelmann, B., Levy, W., Zsolnay, A., Weiss, P., Jakobi, G., Kirchner, M. Moche, W., Braun, K., Schramm, K.W., 2009. Altitudinal and chiral signature of persistent organochlorine pesticides in air, soil, and spruce needles (Picea abies) of the Alps. Environmental Science and Technology 43, 2450-2455.

Sparling, D.W., Fellers, G.M., McConnell, L.L., 2001. Pesticides and amphibian population declines in California. USA Environmental Toxicology and Chemistry 20 1591-1595.

Stocker, J., Scheringer, M., Wegmann, F., Hungerbuhler, K., 2007. Modeling the effect of snow and ice on the global environmental fate and long-range transport potential of semivolatile organic compounds. Environmental Science and Technology 41, 6192-6198.

Tremolada, P., Villa, S., Bazzarin, P., Bizzotto, E., Comolli, R., Vighi, M., 2008. POPs in mountain soils from the Alps and Andes: suggestions for a 'precipitation effect' on altitudinal gradients. Water, Air, and Soil Pollution 188, 93-109.

Van den Berg, M., Birnbaum, L., Bosveld, A.T., Brunstr, M.B., Cook, P., Feeley, M. Giesy, J.P., Hanberg, A., Hasegawa, R., Kennedy, S.W., 1998. Toxic equivalency factors (TEFs) for PCBs, PCDDs, PCDFs for humans and wildlife. Environmental Health Perspectives 106, 775-792.

Wang, P., Zhang, Q.H., Wang, Y.W., Wang, T., Li, X.M., Li, Y.M., Ding, L., Jiang, G.B. 2009. Altitude dependence of polychlorinated biphenyls (PCBs) and polybrominated diphenyl ethers (PBDEs) in surface soil from Tibetan Plateau, China. Chemosphere 76, 1498-1504.

Wang, X.P., Gong, P., Yao, T.D., Jones, K.C., 2010. Passive air sampling of organochlorine pesticides, polychlorinated biphenyls, and polybrominated dipheny ethers across the Tibetan Plateau. Environmental Science and Technology 44, 2988-2993.

Wania, F., Mackay, D., 1993. Global fractionation and cold condensation of low volatility organochlorine compounds in polar regions. AMBIO 22, 10-18.

Wania, F., Mackay, D., 1996. Tracking the distribution of persistent organic pollutants. Environmental Science and Technology 30, 390.

Wania, F., McLachlan, M.S., 2001. Estimating the influence of forests on the overall fate of semivolatile organic compounds using a multimedia fate model. Environmental Science and Technology 35, 582-590.

Wania, F., Westgate, J.N., 2008. On the mechanism of mountain cold-trapping of organic chemicals. Environmental Science and Technology 42, 9092-9098.

Watanabe, I., Sakai, S.-i., 2003. Environmental release and behavior of brominated flame retardants. Environment International 29, 665-682.

Yang, R.Q., Yao, T.D., Xu, B.Q., Jiang, G.B., Zheng, X.Y., 2008. Distribution of organochlorine pesticides (OCPs) in conifer needles in the southeast Tibetan Plateau. Environmental Pollution 153, 92-100.

Yang, R.Q., Wang, Y.W., Li, A., Zhang, Q.H., Jing, C.Y., Wang, T., Wang, P., Li, Y.M., Jiang, G.B., 2010. Organochlorine pesticides and PCBs in fish from lakes of the Tibetan Plateau and the implications. Environmental Pollution 158, 2310-2316.

Zheng, X.Y., Liu, X.D., Liu, W.J., Jiang, G.B., Yang, R.Q., 2009. Concentrations and source identification of organochlorine pesticides (OCPs) in soils from Wolong Natural Reserve. Chinese Science Bulletin 54, 743-751. 